\title{
Desmidiaceae (exceto Cosmarium) de um tributário do Reservatório de Itaipu, Paraná, Brasil
}

\author{
Stefania Biolo ${ }^{1}$, Natália Silveira Siqueira ${ }^{1}$ e Norma Catarina Bueno ${ }^{2,3}$
}

Recebido: 28.12.2006; aceito: 27.07.2008

ABSTRACT - (Desmidiaceae (except Cosmarium) from a tributary of Itaipu Reservoir, State of Paraná, Brazil). Survey of genera Desmidiaceae (except Cosmarium) in a tributary of Itaipu Reservoir. It carried out it qualitative analysis of 60 samples collected in the period from July 2003 to June 2004. Forty-one species, ten varieties which are not the typical of its respective species and an another not typical species were also identified. The Desmidiaceae were represented by the genera: Actinotaenium (1), Closterium (3), Euastrum (5), Micrasterias (5), Octacanthium (1), Onychonema (1), Penium (1), Pleurotaenium (2), Spondylosium (2), Staurastrum (14), Staurodesmus (5) and Xanthidium (1). Staurastrum was the most presented genus, contributing with $34 \%$ of the total wealth. The least presented genera were: Actinotaenium, Octacanthium, Onychonema, Penium and Xanthidium, with one species each totaling 12\%. Micrasterias truncata (Corda) Brébisson ex Ralfs var. pusila G.S. West was found in all stations of collection.

Key words: Brazil, desmids, taxonomy, Zygnemaphyceae

RESUMO - (Desmidiaceae (exceto Cosmarium) de um tributário do Reservatório de Itaipu, Paraná, Brasil). Levantamento florístico das Desmidiaceae (exceto Cosmarium) de um tributário do Reservatório de Itaipu. Realizou-se análise qualitativa de 60 amostras, coletadas no período de julho de 2003 a junho de 2004. Quarenta e uma espécies, dez variedades que não são as típicas de suas respectivas espécies e uma forma igualmente não típica foram identificadas. As Desmidiaceae foram representadas pelos gêneros: Actinotaenium (1), Closterium (3), Euastrum (5), Micrasterias (5), Octacanhtium (1), Onychonema (1), Penium (1), Pleurotaenium (2), Spondylosium (2), Staurastrum (14), Staurodesmus (5) e Xanthidium (1). Staurastrum foi o gênero mais especioso contribuindo com $34 \%$ da riqueza total. Os gêneros menos especiosos foram: Actinotaenium, Octacanthium, Onychonema, Penium e Xanthidium, representados cada um por apenas uma espécie, juntos somaram 12\% do total. Micrasterias truncata (Corda) Brébisson ex Ralfs var. pusilla G.S. West foi encontrada em todas as estações de coleta.

Palavras-chave: Brasil, desmídeas, taxonomia, Zygnemaphyceae

\section{Introdução}

A classe Zygnemaphyceae constitui um grupo relevante nos ambientes aquáticos continentais, pela alta diversidade morfológica comparada aos demais grupos de algas verdes. Representantes da família Desmidiaceae distribuem-se de forma cosmopolita e são abundantes em lagos, tanques e rios oligotróficos e mesotróficos (Wehr \& Sheat 2003). As desmídeas destacam-se entre os diversos grupos algais, principalmente, pela riqueza específica (Felisberto \& Rodrigues 2002) e podem ser encontradas no perifíton, no metafíton e no planctôn (Margalef 1983).
Doze trabalhos compreendem o conhecimento sobre as desmídeas do Estado do Paraná: BittencourtOliveira (1993a, b), Bittencourt-Oliveira \& Castro (1993), Bittencourt-Oliveira \& Mecenas (1994), Cecy (1993), Cecy et al. (1997), Picelli-Vicentim et al. (2001), Silva \& Cecy (2004) e Felisberto \& Rodrigues (2007). Os trabalhos de Felisberto (2003), Cetto et al. (2004), Felisberto \& Rodrigues (2005), Algarte et al. (2006) incluem listagens de espécies em trabalhos de cunho ecológico.

Este trabalho teve como objetivo o estudo taxonômico das Desmidiaceae (exceto Cosmarium) de um tributário do Reservatório de Itaipu, provenientes

1. Programa de Pós-graduação em Ecologia de Ambientes Aquáticos Continentais, Universidade Estadual de Maringá, Departamento de Biologia, Nupélia, Av. Colombo 5790, 87020-900 Maringá, PR, Brasil

2. Universidade Estadual do Oeste do Paraná, Centro de Ciências Biológicas e da Saúde, Rua Universitária 2069, 85814-110 Cascavel, PR, Brasil

3. Autor para correspondência: ncbueno@unioeste.br 
de cinco estações de amostragem ao longo de um ano de estudo.

\section{Material e métodos}

O Reservatório de Itaipu localiza-se na divisa Brasil-Paraguai $\left(24^{\circ} 05^{\prime}\right.$ a $25^{\circ} 33^{\prime} \mathrm{S}$ e $54^{\circ} 00^{\prime}$ a $\left.54^{\circ} 37^{\prime} \mathrm{W}\right)$, com uma área total de $170 \mathrm{~km}$ de extensão e $12 \mathrm{~km}$ de largura (Agostinho et al. 1999). O rio São Francisco Falso $\left(38,8 \mathrm{~km}^{2}\right)$ é o principal formador da área alagada do município de Santa Helena, no oeste do Paraná (figura 1).

As amostras estudadas foram coletadas mensalmente, no período de julho de 2003 a junho de 2004, em cinco estações de amostragem ao longo do Rio São Francisco, totalizando 60 amostras, as quais seguem: Estação 1, 24'52'41''S e 54'13'35'W;

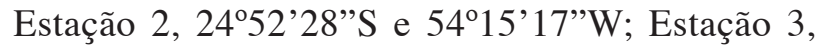
24'51'52"S e 54 16'02"W; Estação 4, 24'51'30"'S e

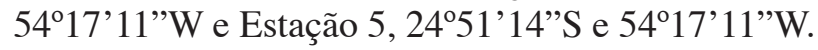
As amostras foram obtidas com rede de plâncton de malha de $25 \mu \mathrm{m}$ de abertura e imediatamente preservadas em solução Transeau, na proporção 1:1 (Bicudo \& Menezes 2006).

Para as análises qualitativas foram preparadas lâminas temporárias, em média 10 lâminas por amostra ou até não ocorrerem táxons diferentes. A análise das lâminas e as ilustrações foram realizadas com microscópio binocular e câmara clara em aumento de 400 e 1000x. As amostras encontram-se depositadas no Herbário da Universidade Estadual de Maringá (HUEM). As medidas (em um) estão

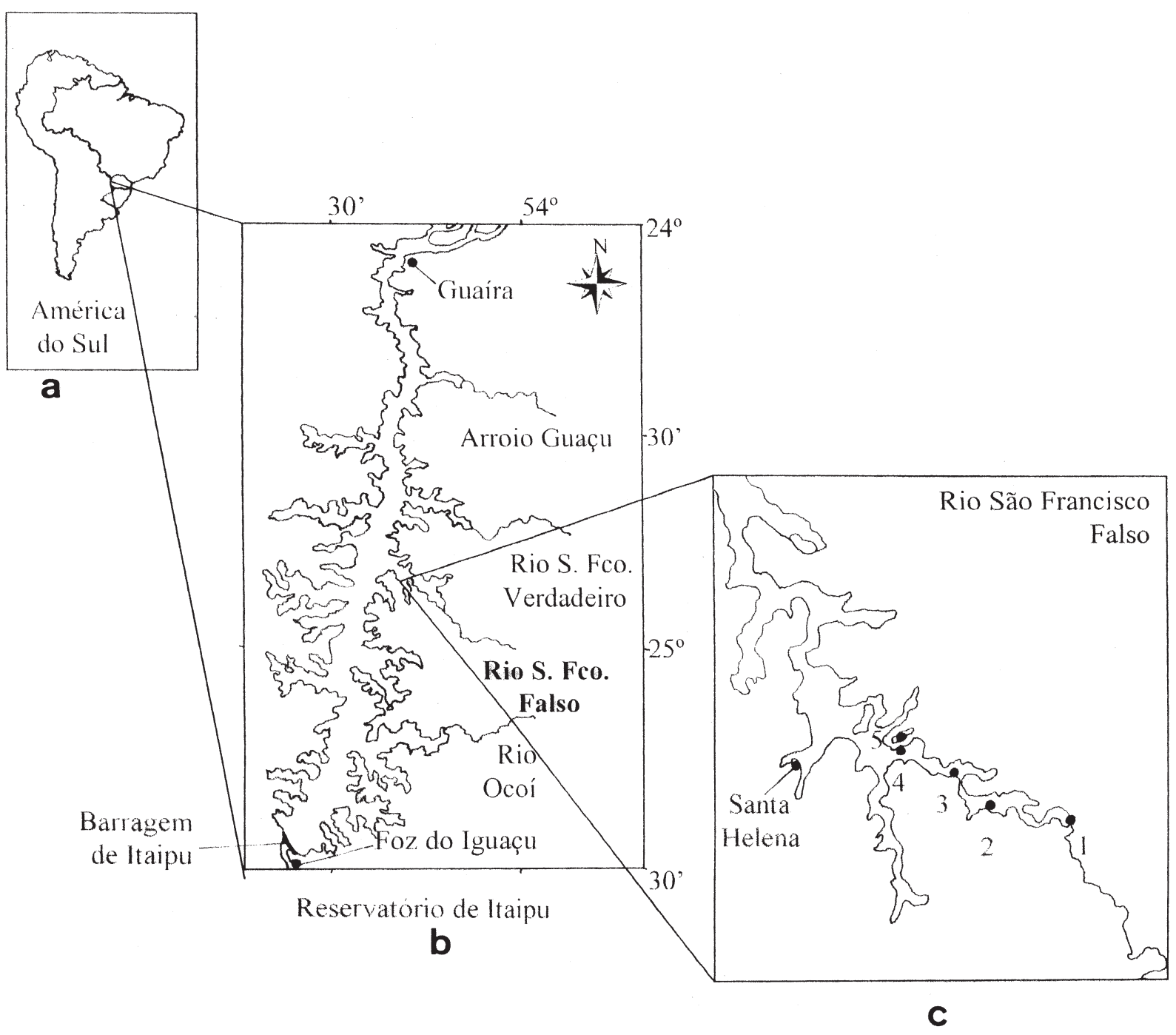

Figura 1. Mapa da área de estudo (a), Reservatório de Itaipu (b) e localização das estações de coleta (c) no rio São Francisco Falso, Paraná, Brasil. 
representadas pelos símbolos: diâm. = diâmetro; compr. = comprimento; larg. = largura; esp. = espinho; proc. $=$ processo .

\section{Resultados e Discussão}

O levantamento florístico das Desmidiaceae (exceto Cosmarium) de um tributário do Reservatório de Itaipu registrou a ocorrência de quarenta e uma espécies, onze variedades que não são as típicas de suas respectivas espécies e uma forma taxonômica igualmente não típica, distribuídos nos seguintes gêneros: Actinotaenium (1), Closterium (3), Euastrum (5), Micrasterias (5), Octacanthium (1), Onychonema (1), Penium (1), Pleurotaenium Nägeli (2), Spondylosium (2), Staurastrum (14), Staurodesmus (5) e Xanthidium (1). Staurastrum foi o gênero mais especioso contribuindo com $34 \%$ da riqueza total. Os gêneros menos especiosos foram Actinotaenium, Octacanthium, Onychonema, Penium e Xanthidium, representados cada um por apenas uma espécie, que juntos somaram $12 \%$ do total. Pleurotaenium sp. não pode ser identificado além do nível gênero, já que não foram observados cloroplastos e pirenóides, caracteres que diferenciam P. ovatum (Nordstedt) Nordstedt de $P$. maskellii Suxena \& Venkateswarlu.

Actinotaenium wollei (West \& G.S. West) Teiling ex Růžička \& Pouzar var. wollei, Folia Geobot. et Phytotax. 13: 61. 1978 =Cosmarium globosum Bulheim var. wollei West \& G.S. West, Trans. Linn. Soc. London, Bot. II, 5(5): 252.

Figura 2

Célula 1,1-1,3 vezes mais longas que largas, 31,246,9 $\mu \mathrm{m}$ compr., 28-36,7 $\mu \mathrm{m}$ larg., istmo 22,0-30,6 $\mu \mathrm{m}$ larg.; semicélula semicircular, constrição mediana rasa, seno aberto; parede celular pontuada, com exceção da região do istmo, cloroplasto 1, estelóide, 1 pirenóide; vista apical circular.

Materiais examinados: BRASIL. Paraná: Santa Helena, rio São Francisco Falso, Estação 2, 1-VII2003, N.C. Bueno 855 (HUEM); idem, 3-II-2004, N.C. Bueno 913 (HUEM); Estação 3, 6-X-2003, N.C. Bueno 883 (HUEM); idem, 4-XI-2003, N.C. Bueno 888 (HUEM).

Os espécimes de Actinotaenium assemelhase muito a Cosmarium e diferem deste último por apresentar cloroplasto estelóide e vista apical circular (Bicudo \& Menezes 2006).
Closterium dianae Ehrenberg ex Ralfs var. dianae, Brit. Desm.: 168. 1848.

Figura 3

Célula lunada, 6,9-8 vezes mais longa que larga, 67,2-110 $\mu \mathrm{m}$ compr., 8,4-16 $\mu \mathrm{m}$ larg.; margem dorsal convexa, margem ventral côncava, ápices obtusoarredondados; parede celular lisa, cloroplasto axial, 4-8 pirenóides.

Materiais examinados: BRASIL. PARANÁ: Santa Helena, rio São Francisco Falso, Estação 2, 6-X-2003, N.C. Bueno 882 (HUEM); idem, 10-III-2004, N.C. Bueno 918 (HUEM); idem, 5-IV-2004, N.C. Bueno 925 (HUEM); Estação 4, 28-VII-2003, N.C. Bueno 862 (HUEM); Estação 5, 1-IX-2003, N.C. Bueno 874 (HUEM).

Closterium incurvum Brébisson var. incurvum, Mém. Soc. Imp. Sci. nat. Cherbourg. 4. 1856.

Figura 4

Célula lunada, 6,3-5,8 vezes mais longa que larga, 36,8-52,5 um compr., 6,4-8,4 um larg.; margem dorsal convexa, margem ventral côncava, ápices acuminados; parede celular aparentemente lisa, cloroplasto axial, 1-2 pirenóides.

Materiais examinados: BRASIL. PARAnÁ: Santa Helena, rio São Francisco Falso, Estação 1, 8-XII2003, N.C. Bueno 902 (HUEM); Estação 2, 6-X-2003, N.C. Bueno 882 (HUEM); Estação 5, 1-IX-2003, N.C. Bueno 874 (HUEM); idem, 6-X-2003, N.C. Bueno 885 (HUEM); idem, 4-XI-2003, N.C. Bueno 890 (HUEM).

Closterium incurvum var. incurvum assemelhase a Closterium venus Kützing ex Ralfs e difere por apresentar curvatura celular pronunciada e o ápice das células acuminado.

Closterium moniliferum (Bory) Ehrenberg ex Ralfs var. moniliferum, Brit. Desm. 1848.

Figura 5

Célula lunada, 4,5-4,9 vezes mais longa que larga, 183,6-259,1 um compr., 40,8-53,1 um larg.; margem dorsal convexa, margem ventral côncava, inflada ou não na região mediana, ápices arredondados; parede celular lisa, cloroplasto axial, 7-12 pirenóides em série mediana.

Materiais examinados: BRASIL. Paraná: Santa Helena, rio São Francisco Falso, Estação 1, 1-VII-2003, 
N.C. Bueno 859 (HUEM); idem, 1-VII-2003, N.C. Bueno 859 (HUEM); idem, 1-IX-2003, N.C. Bueno 870 (HUEM); Estação 2, 1-VII-2003, N.C. Bueno 860 (HUEM); idem, 1-VII-2003, N.C. Bueno855 (HUEM); idem, 6-X-2003, N.C. Bueno 882 (HUEM); idem, $17-$ VI-2004, N.C. Bueno 937 (HUEM); Estação 3, 1-VII2003, N.C. Bueno 861 (HUEM); idem, 8-XII-2003, N.C. Bueno 904 (HUEM); idem, 10-III-2004, N.C. Bueno 919 (HUEM); idem, 4-V-2004, N.C. Bueno 933 (HUEM); Estação 4, 1-VII-2003, N.C. Bueno 857 (HUEM); idem, 28-VII-2003, N.C. Bueno 862 (HUEM); idem, 6-X-2003, N.C. Bueno 884 (HUEM); idem, 8-XII-2003, N.C. Bueno 905 (HUEM); idem, 19-I-2004, N.C. Bueno 910 (HUEM); idem, 3-II-2004, N.C. Bueno 915 (HUEM).

Closterium moniliferum var. moniliferum difere de Closterium ehrenbergii Meneghini ex Ralfs devido ao arranjo e número de pirenóides no cloroplasto, mais numerosos e esparsos na segunda espécie.

Euastrum abruptum Nordestedt var. abruptum, Vidensk. Meddr. dansk naturh. Foren. 14-15: 217. 1887.

Figura 6

Célula 1,5 vezes mais longa que larga, 36,8-48,3 $\mu \mathrm{m}$ compr., 24-31,5 $\mu \mathrm{m}$ larg., istmo $9 \mu \mathrm{m}$; semicélula subtrapeziforme, 3-lobada, constrição mediana profunda, incisão apical profunda, aberta; lobos basais bilobulados, espinhos e grânulos submarginais; lobo apical subretangular, com 1 espinho nos ângulos, margem apical truncada, com espinhos e grânulos submarginais; parede celular lisa, 1 protrusão facial mediana com 3 grânulos, cloroplasto axial, 1 pirenóide.

Materiais examinados: BRASIL. ParanÁ: Santa Helena, rio São Francisco Falso, Estação 2, 1-VII2003, N.C. Bueno 855 (HUEM); idem, 1-IX-2003, N.C. Bueno 871 (HUEM); Estação 3, 6-X-2003, N.C. Bueno 883 (HUEM); Estação 4, 1-VII-2003, N.C. Bueno 857 (HUEM); Estação 5, 1-IX-2003, N.C. Bueno 874 (HUEM); idem, 5-IV-2004, N.C. Bueno 928 (HUEM).

Euastrum abruptum Nordstedt var. lagoense (Nordstedt) Krieger Rabenhorst, KryptogamenFl. Deutschl. 13(1): 609. 1937 = Euastrum binale (Turpin) Ehrenberg f. lagoensis Nordstedt, Vidensk. Meddr. Dansk naturh. Foren. 14-15: 218. 1970.
Figura 7

Célula 1,3 vezes mais longa que larga, 20-24,5 $\mu \mathrm{m}$ compr., 16-18,4 $\mu \mathrm{m}$ larg., istmo 4-6,1 $\mu \mathrm{m}$.

Materiais examinados: BRASIL. Paraná: Santa Helena, rio São Francisco Falso, Estação 1, 19-I-2004, N.C. Bueno 907 (HUEM); idem, 1-IX-2003, N.C. Bueno 870 (HUEM); Estação 2, 1-VII-2003, N.C. Bueno 855 (HUEM); Estação 5, 28-VII-2003, N.C. Bueno 863 (HUEM); idem, 6-X-2003, N.C. Bueno 885 (HUEM).

Euastrum abruptum var. lagoense difere da variedade típica da espécie por apresentar dimensões celulares menores, margens laterais desprovidas de dentículos e ausência de poros diferenciados na superfície da célula.

Euastrum quebecense Irene-Marie, Flore Desm. 132: 16-17. 1939.

Figura 8

Célula 1,6-1,8 vezes mais longa que larga, 38,4$44 \mu \mathrm{m}$ compr., 21,6-28 $\mu \mathrm{m}$ larg., istmo 4,8-6 um; semicélula trapeziforme, 3-lobada, constrição mediana profunda, incisão apical profunda, aberta, com espessamento da parede; lobos basais com espinhos e grânulos nos ângulos; lobo apical sub-retangular, com espinho e grânulo, margens laterais levemente infladas na região mediana, margem apical truncada, inflada na porção mediana, ângulos apicais com 1 espinho; parede celular lisa, 1 protrusão mediana com 2 grânulos, cloroplasto axial, 1 pirenóide.

Materiais examinados: BRASIL. PARAnÁ: Santa Helena, rio São Francisco Falso, Estação 2, 1-IX-2003, N.C. Bueno 871 (HUEM); Estação 3, 1-IX-2003, N.C. Bueno 872 (HUEM); Estação 5, 6-X-2003, N.C. Bueno 885 (HUEM); idem, 4-XI-2003, N.C. Bueno 890 (HUEM); idem, 8-XII-2003, N.C. Bueno 906 (HUEM); idem, 3-II-2004, N.C. Bueno 916 (HUEM); idem, 4-V-2004, N.C. Bueno 935 (HUEM).

Os exemplares examinados apresentaram dimensões celulares inferiores aos encontrados em literatura especializada.

Euastrum rectangulare Fritsch \& Rich, Trans. Roy. Soc. S. Afr. 25(2): 174. 1937.

Figura 9

Célula 1,2-1,3 vezes mais longa que larga, 14$18 \mu \mathrm{m}$ compr., 12-14 $\mu \mathrm{m}$ larg., istmo 3,2-6 $\mu \mathrm{m}$; 

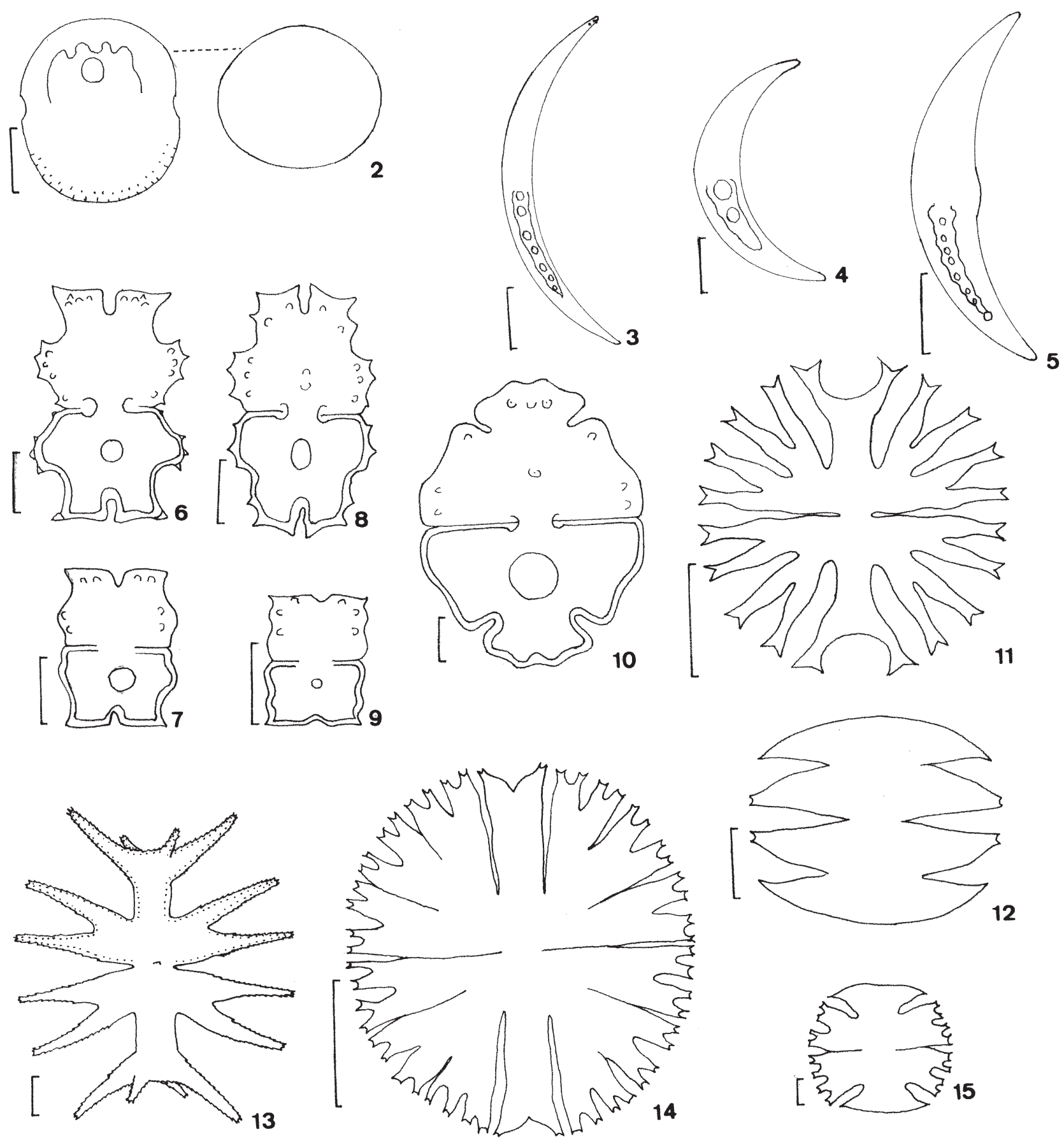

\section{5}

Figura 2. Actinotaenium wollei var. wollei (barra =10,2 $\mu \mathrm{m})$. Figura 3. Closterium dianae var. dianae (barra $=20 \mu \mathrm{m})$. Figura 4. Closterium incurvum var. incurvum (barra $=10 \mu \mathrm{m}$ ). Figura 5. Closterium moniliferum var. moniliferum (barra $=50 \mu \mathrm{m}$ ). Figura 6. Euastrum abruptum var. abruptum (barra $=10 \mu \mathrm{m}$ ). Figura 7. Euastrum abruptum var. lagoense (barra $=10 \mu \mathrm{m})$. Figura 8 . Euastrum quebecense (barra $=20 \mu \mathrm{m})$. Figura 9. Euastrum rectangulare (barra $=10 \mu \mathrm{m})$. Figura 10. Euastrum subintegrum var. brasiliense. Figura 11. Micrasterias furcata var. furcata (barra $=50 \mu \mathrm{m}$ ). Figura 12. Micrasterias laticeps var. laticeps (barra $=40 \mu \mathrm{m})$. Figura 13. Micrasterias mahabuleshwarensis var. amazonensis (barra $=20 \mu \mathrm{m})$. Figura 14. Micrasterias rotata (barra $=50 \mu \mathrm{m})$. Figura 15. Micrasterias truncata var. pusilla $($ barra $=10 \mu \mathrm{m})$. 
semicélula retangular, constrição mediana profunda, incisão apical pouco profunda, aberta, em formato de V; lobos basais tão largos quanto o lobo apical, margens laterais 2-onduladas, com 1 grânulo em cada ondulação; margem apical truncada, levemente ondulada, 1 grânulo em cada lado da incisão apical; parede celular lisa, cloroplasto axial, 1 pirenóide.

Materiais examinados: BRASIL. PARAnÁ: Santa Helena, rio São Francisco Falso, Estação 2, 6-X-2003, N.C. Bueno 882 (HUEM); Estação 4, 28-VII-2003, N.C. Bueno 862 (HUEM); Estação 5, 1-IX-2003, N.C. Bueno 874 (HUEM); idem, 5-IV-2004, N.C. Bueno 928 (HUEM).

Euastrum rectangulare assemelha-se a $E$. denticulatum (Kirchner) Gay var. rectangulare West \& G.S. West. No entanto, indivíduos de $E$. denticulatum var. rectangulare apresentam dimensões celulares maiores, ângulos basais arredondados com dentículos e incisão apical em forma de "U".

Euastrum subintegrum Nordstedt var. brasiliense Grönblad, Acta Soc. Sci. Fenn. 2(6): 14. 1945.

Figura 10

Célula 1,3 vezes mais longa que larga, 65,6 $\mu \mathrm{m}$ compr., 51,2 $\mu \mathrm{m}$ larg., istmo $8 \mu \mathrm{m}$; semicélula subtrapeziforme, 3-lobada, constrição mediana profunda; lobos basais bilobulados, incisão entre os lobos basais e apical profunda, aberta, vértice espessado; lobo apical subcuneiforme, amplo, margem apical biconvexa, espessamento subapical; parede celular aparentemente lisa, 2 protuberâncias centrais, 4 escrobículos com 1 poro central cada, cloroplasto axial, 1 pirenóide.

Materiais examinados: BRASIL. ParanÁ: Santa Helena, rio São Francisco Falso, Estação 2, 6-X-2003, N.C. Bueno 882 (HUEM).

Euastrum subintegrum var. brasiliense difere da variedade típica da espécie pela presença de duas protuberâncias localizadas na região mediana da célula.

Micrasterias furcata C. Agardh ex Ralfs var.furcata, Brit. Desm.: 73. 1848.

Figura 11

Célula tão longa quanto larga ou 1,2 vezes mais longa que larga, 140-166 $\mu \mathrm{m}$ compr., 116-160 $\mu \mathrm{m}$ larg., istmo 10-16 $\mu \mathrm{m}$; semicélula de contorno semicircular, 5-lobada, constrição mediana profunda, incisões interlobulares profundas, abertas; lobos laterais e basais divididos em 2 lóbulos 2-denticulados; lobo apical subcilíndrico, margens retas, paralelas, ápice retuso, ângulos projetados formando processos divergentes 2-denticulados; parede celular finamente pontuada.

Materiais examinados: BRASIL. ParanÁ: Santa Helena, rio São Francisco Falso, Estação 2, 17-VI2004, N.C. Bueno 937 (HUEM); Estação 5, 1-IX2003, N.C. Bueno 874 (HUEM); idem, 4-XI-2003, N.C. Bueno 890 (HUEM); idem, 19-I-2004, N.C. Bueno 911 (HUEM); idem, 5-IV-2004, N.C. Bueno 928 (HUEM); idem, 17-VI-2004, N.C. Bueno 940 (HUEM).

Micrasterias laticeps Nordstedt var. laticeps, Vidensk. Meddr dansk naturh. Foren. 14-15: 220. 1869.

Figura 12

Célula 1,1-1,2 vezes mais larga que longa, 120184,8 $\mu \mathrm{m}$ compr., 142-210 $\mu \mathrm{m}$ larg., istmo 20-30 $\mu \mathrm{m}$; semicélula de contorno semicircular, 3-lobada, constrição mediana profunda, incisões interlobulares profundas, acutangulares; lobos basais 2-denticulados, lobo apical transversalmente fusiforme, margem apical convexa ou reta na porção mediana, ângulos acuminados; parede celular finamente pontuada.

Materiais examinados: BRASIL. PARANÁ: Santa Helena, rio São Francisco Falso, Estação 2, 1-VII2003, N.C. Bueno 855 (HUEM); idem, 1-IX-2003, N.C. Bueno 871 (HUEM); idem, 6-X-2003, N.C. Bueno 882 (HUEM); idem, 4-V-2004, N.C. Bueno 932 (HUEM); Estação 3, 6-X-2003, N.C. Bueno 883 (HUEM).

Micrasterias mahabuleshwarensis Hobson var. amazonensis Förster, Amazoniana 2(1-2): 40. 1969.

Figura 13

Célula 1,1 vezes mais longa que larga, 132167,3 um compr., 118-157,1 um larg., istmo 18,4-30 $\mu \mathrm{m}$; semicélula de contorno semielíptico, 5-lobada, constrição mediana profunda, incisões interlobulares profundas, abertas; lobos laterais e basais cônicotruncados, não-divididos, 3-denticulados; lobo apical subcilíndrico, ápice retuso, ângulos projetados formando processos divergentes 3-denticulados, truncados, com 1 par de processos acessórios na base dos ângulos; parede celular com grânulos. 
Materiais examinados: BRASIL. Paraná: Santa Helena, rio São Francisco Falso, Estação 2, 6-X2003, N.C. Bueno 882 (HUEM); idem, 4-V-2004, N.C. Bueno 932 (HUEM); Estação 4, 1-VII-2003, N.C. Bueno 857 (HUEM); Estação 5, 5-IV-2004, N. C. Bueno 928 (HUEM); idem, 4-V-2004, N.C. Bueno 935 (HUEM).

Micrasterias mahabuleshwarensis var. amazonensis difere da variedade típica da espécie pelo formato rombóide da célula na vista apical, pela presença de papilas com 2-4 grânulos nos ângulos e espinhos pequenos na base de cada semicélula.

Micrasterias rotata (Grenville) Ralfs ex Ralfs var. rotata, Ann. Mag. Nat. Hist. 14: 259. 1844 三 Echinella rotata Greville in Hooker, Brit. Flora 2: 398. 1833.

Figura 14

Célula 1,1 vezes mais larga que longa, 221,2 $\mu \mathrm{m}$ compr., $210 \mu \mathrm{m}$ larg., istmo 24,4 $\mu \mathrm{m}$; semicélula de contorno semicircular, 5-lobada, constrição mediana profunda, incisões interlobulares profundas, lineares, semi-abertas; lobos basal e laterais divididos em 8 lóbulos, 2-denticulados, por 7 incisões; lobos basais divididos em 4 lóbulos, 2-denticulados, por 3 incisões; lobo apical subcilíndrico, margens retilíneas, ápice chanfrado, ângulos projetados, 2-denticulados; parede celular lisa.

Material examinado: BRASIL. PARANÁ: Santa Helena, rio São Francisco Falso, Estação 2, 19-I-2004, N.C. Bueno 908 (HUEM).

Micrasterias truncata (Corda) Brébisson ex Ralfs var. pusilla G.S. West, Mém. Soc. Neuchât. Sci. Nat. 5: $1035.1914 \equiv$ Micrasterias truncata (Corda) Brébisson f. Borge, Ark. Bot. 15(13): 66, pl. 5, fig. 24. 1918.

Figura 15

Célula 1,1 vezes mais larga que longa, 48-58,8 $\mu \mathrm{m}$ compr., 54-63 $\mu \mathrm{m}$ larg., istmo 10,2-14 $\mu \mathrm{m}$; semicélula de contorno semicircular, 5-lobada, constrição mediana profunda, incisões interlobulares levemente abertas; lobos laterais e basais 2-lobulados, 2-denticulados, incisão entre os lóbulos pouco profunda, aberta; lobo apical subfusiforme, ápice truncado ou levemente convexo, às vezes presença de uma depressão mediana leve, ângulos acuminados; parede celular finamente pontuada.
Materiais examinados: BRASIL. PAraná: Santa Helena, rio São Francisco Falso, Estação 1, 1-IX2003, N.C. Bueno 870 (HUEM); idem, 19-I-2004, N.C. Bueno 907 (HUEM); Estação 2, 1-IX-2003, N.C. Bueno 871 (HUEM); Estação 3, 1-VII-2003, N.C. Bueno 861 (HUEM); idem, 6-X-2003, N.C. Bueno 883 (HUEM); idem, 8-XII-2003, N.C. Bueno 904 (HUEM); Estação 4, 1-VII-2003, N.C. Bueno 857 (HUEM); Estação 5, 17-VI-2004, N.C. Bueno 940 (HUEM).

Micrasterias truncata var. pusilla difere da variedade típica da espécie devido aos ângulos acuminados dos lobos apicais, menores dimensões celulares e células mais largas do que longas.

Octacanthium mucronulatum (Nordstedt) Compère var. mucronulatum, Nova Hedwigia 112: 505. 1996 三Staurodesmus mucronulatus (Nordstedt) Compère. Táxon 25 (2/3): 360. 1976.

Figura 16

Célula 1,5 vezes mais larga que longa, 32-34 $\mu \mathrm{m}$ compr., $48 \mu \mathrm{m}$ larg., istmo $12 \mu \mathrm{m}$; semicélula elíptico fusiforme, margens laterais levemente convexas, ângulos basais com espinhos curtos, convergentes, margem apical convexa, dois espinhos; parede celular finamente pontuada, cloroplasto com dois pirenóides.

Material examinado: BRASIL. Paraná: Santa Helena, rio São Francisco Falso, Estação 2, 3-II-2004, N.C. Bueno 913 (HUEM).

Onychonema laeve Nordstedt var. laeve, Vidensk. Meddr dansk Naturh. Foren. Kjöbenhavn 14-15: 206. 1869.

Figura 17

Filamentos torcidos, célula 1,7 vezes mais larga que longa, 12,6-17,6 $\mu \mathrm{m}$ compr., 21-29,6 $\mu \mathrm{m}$ larg. (sem espinho), istmo 3,2 $\mu \mathrm{m}$; semicélula de contorno transversalmente oblongo, constrição mediana profunda, margem lateral com 1 espinho, convergente, margem apical truncada, 2 processos unindo as células; parede celular lisa, cloroplasto axial, 1 pirenóide.

Materiais examinados: BRASIL. PARANÁ: Santa Helena, rio São Francisco Falso, Estação 4, 1-VII2003, N.C. Bueno 867 (HUEM); Estação 5, 1-IX2003, N.C. Bueno 874 (HUEM); idem, 5-IV-2004, N. C. Bueno 928 (HUEM). 
Penium margaritaceum (Ehrenberg) Brébisson ex Ralfs var. margaritaceum, Brit. Desm. 149. 1848 $\equiv$ Closterium margaritaceum Ehrenberg, Infus., p. 95, pl. 6, fig. 3, 1838.

Figura 18

Célula cilíndrica, alongada, 4,4-7,5 vezes mais longa que larga, 71,4-183,6 $\mu \mathrm{m}$ compr., 16,3-24,5 $\mu \mathrm{m}$ larg.; constrição mediana ausente ou pouco evidente, margens paralelas, ápice arredondado; parede celular pontuada irregularmente, presença de zonas de alongamento.

Materiais examinados: BRASIL. Paraná: Santa Helena, rio São Francisco Falso, Estação 3, 1-VII2003, N.C. Bueno 861 (HUEM); idem, 1-IX-2003, N.C. Bueno 874 (HUEM); idem, 4-XI-2003, N.C. Bueno 888 (HUEM); idem, 10-III-2004, N.C. Bueno 919 (HUEM); idem, 5-IV-2004, N.C. Bueno 926 (HUEM).

Pleurotaenium ehrenbergii (Brébisson) De Bary var. ehrenbergii, Untersuch. Fam. Conjugatae 75. 1858

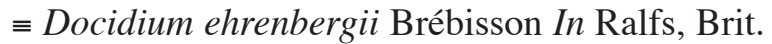
Desm. 157. 1848.

Figura 19

Célula 20,2-21,5 vezes mais longa que larga, 687,5-764,5 um compr., 32-37,8 um larg.; semicélula subcilíndrica, constrição mediana rasa, margens laterais retilíneas, com 1 intumescência basal e 1-4 ondulações acima da intumescência; ápice truncado, grânulos visíveis frontalmente, parede celular pontuada.

Materiais examinados: BRASIL. PARAnÁ: Santa Helena, rio São Francisco Falso, Estação 2, 1-IX2003, N.C. Bueno 871 (HUEM); Estação 3, 6-X-2003, N.C. Bueno 883 (HUEM); Estação 5, 4-XI-2003, N.C. Bueno 890 (HUEM); idem, 1-IX-2003, N.C. Bueno 874 (HUEM); idem, 5-IV-2004, N. C. Bueno 928 (HUEM).

\section{Pleurotaenium sp.}

Figura 20

Célula 2,9 vezes mais longa que larga, $376 \mu \mathrm{m}$ compr., $130 \mu \mathrm{m}$ larg., istmo 72,3 $\mu \mathrm{m}$ larg.; semicélula subovada, margens laterais amplamente convexas, afiladas em direção ao ápice; ápice truncado, com 1 anel de 6 grânulos visíveis em vista frontal; parede celular pontuada, cloroplastos e pirenóides não observados.
Materiais examinados: BRASIL, PARANÁ: Santa Helena, rio São Francisco Falso, Estação 2, 06-X2003, N.C. Bueno 882 (HUEM).

O único exemplar encontrado durante a análise das amostras poderia ser identificado como Pleurotaenium ovatum (Nordstedt) Nordstedt ou P. maskellii Suxena \& Venkateswarlu. De acordo com Sormus (1996), a primeira espécie apresenta cloroplastos fitáceos com vários pirenóides enquanto que a segunda espécie, os cloroplastos consistem de placas irregulares com número variável de pirenóides. Não foi possível observar nenhuma das características diagnósticas no exemplar examinado.

Spondylosium panduriforme (Heimerl) Teiling var. limneticum (West \& G.S.West) Förster, Archiv für Hydrobiologie 63(4): 377. 1983 E Cosmarium moniliforme (Turpin) Ralfs var. limneticum W. \& G. S. West, p. 23, t. 67, fig. 6-7. 1908.

Figura 21

Filamento não-torcido, célula 1,6-1,8 vezes mais longa que larga, 36-40 $\mu \mathrm{m}$ compr., 20-24 $\mu \mathrm{m}$ larg., istmo 12-15,6 $\mu \mathrm{m}$, unidas pela margem apical angulosa da célula; semicélulas circulares, constrição mediana rasa, alongada, seno arredondado; margens laterais arredondadas, margem apical elevada na porção mediana; parede celular lisa, espessa, cloroplasto loboestelóide, 1 pirenóide.

Materiais examinados: BRASIL. PARANÁ: Santa Helena, rio São Francisco Falso, Estação 5, 3-II-2004, N.C. Bueno 916 (HUEM); idem, 5-IV-2004, N.C. Bueno 928 (HUEM).

Células isoladas de Spondylosium panduriforme var. limneticum, espécie de hábito filamentoso, podem ser facilmente confundidas e identificadas como Cosmarium moniliforme (Turpin) Ralfs. No entanto C. moniliforme (Turpin) Ralfs célula globosa, seno agudo, istmo estreitado, parede celular delgada e cloroplasto pseudoestelóide (Teiling 1952).

Spondylosium pulchrum (Bailey) Archer var. pulchrum, Pritchard's Infusoria 724. 1861 三 Sphaerozosma pulchrum Bailey in Ralfs, British Desmidieae. 209, pl. 35, fig. 2. 1848.

Figura 22

Filamento torcido, célula 1,7 vezes mais larga que longa, 28-35,6 um compr., 47-60 $\mu \mathrm{m}$ larg., istmo $16,7 \mu \mathrm{m}$, unidas por processos cilíndricos, truncados, 

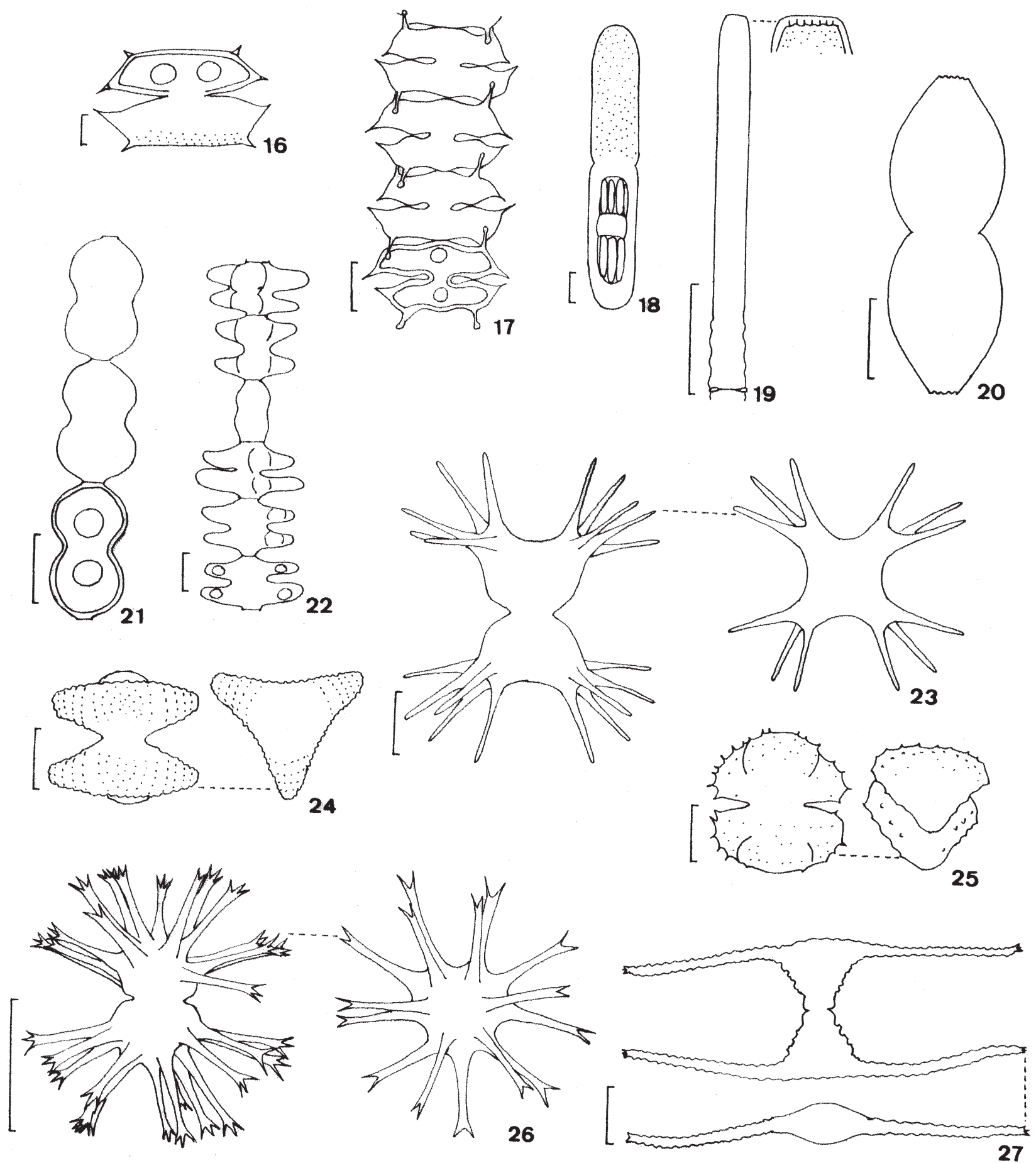

Figura 16. Octacanthium mucronulatum var. mucronulatum (barra $=10 \mu \mathrm{m})$. Figura 17. Onychonema laeve var. laeve $($ barra $=10 \mu \mathrm{m})$. Figura 18. Penium margaritaceum var. margaritaceum $($ barra $=10 \mu \mathrm{m})$. Figura 19. Pleurotaenium ehrenbergii var. ehrenbergii $($ barra $=$ $101,5 \mu \mathrm{m})$. Figura 20. Pleurotaenium sp (barra $=94 \mu \mathrm{m})$. Figura 21. Spondylosium panduriforme var. limneticum $(\mathrm{barra}=20 \mu \mathrm{m})$. Figura 22. Spondylosium pulchrum var. pulchrum (barra $=20 \mu \mathrm{m})$. Figura 23. Staurastrum brasiliense var. brasiliense $($ barra $=20 \mu \mathrm{m})$. Figura 24. Staurastrum dilatatum var. dilatatum (barra $=10 \mu \mathrm{m}$ ). Figura 25. Staurastrum hirsutum (barra $=10 \mu \mathrm{m})$. Figura 26. Staurastrum leptacanthum var. borgei $($ barra $=50 \mu \mathrm{m})$. Figura 27. Staurastrum leptocladum var. insigne $($ barra $=20 \mu \mathrm{m})$. 
da margem apical da célula; semicélula oblongas, constrição mediana profunda, margens laterais amplamente arredondadas ou retas, assimétricas, margem apical com uma elevação formando um processo cilíndrico, truncado, parede celular lisa.

Materiais examinados: BRASIL. PARAnÁ: Santa Helena, rio São Francisco Falso, Estação 2, 5-IV-2004, N.C. Bueno 925 (HUEM); Estação 5, 19-I-2004, N.C. Bueno 911 (HUEM).

Staurastrum brasiliense Nordstedt var. brasiliense, Videsnk. Meddr f. Naturh. Foren. Kjöbenhavn (14/15): 227. 1869.

Figura 23

Célula 1,2-1,3 vezes mais longa que larga (sem espinhos), 100-126,4 $\mu \mathrm{m}$ compr., 81,6-103 $\mu \mathrm{m}$ larg. (com esp.), 39,2-56 um compr., 30-56,8 $\mu \mathrm{m}$ larg. (sem espinhos), istmo 12,0-16,8 $\mu \mathrm{m}$; semicélulas trapeziformes, constrição mediana rasa, margens laterais convexas, margem apical reta com 1 espinho na porção mediana, ângulos formando processo com 3 espinhos longos; parede celular lisa, vista apical 4-angular, margens côncavas entre os ângulos, processos com 3 espinhos divergentes.

Materiais examinados: BRASIL. Paraná: Santa Helena, rio São Francisco Falso, Estação 2, 6-X-2003, N.C. Bueno 882 (HUEM); Estação 5, 6-X-2003, N.C. Bueno 885 (HUEM); idem, 10-III-2004, N.C. Bueno 921 (HUEM); idem, 5-IV-2004, N.C. Bueno 928 (HUEM).

Staurastrum dilatatum Ehrenberg ex Ralfs var. dilatatum, Brit. Desm. 133. 1848.

Figura 24

Célula tão longa quanto larga, ou levemente mais larga, 16,8-22,4 $\mu \mathrm{m}$ compr., 16-24,5 $\mu \mathrm{m}$ larg., istmo 4-9,2 $\mu \mathrm{m}$; semicélulas elípticas a subfusiformes, constrição mediana profunda, margens laterais côncavas, margem apical convexa, ângulos arredondados, grânulos dispostos em séries concêntricas ao redor dos ângulos e séries regulares pela célula; parede celular finamente granulosa; vista apical 3 ou 4-angular, margens côncavas entre os ângulos arredondados, grânulos dispostos em círculos ao redor dos ângulos.

Materiais examinados: BRASIL. Paraná: Santa Helena, rio São Francisco Falso, Estação 2, 5-IV-2004,
N.C. Bueno 925 (HUEM); idem, 1-IX-2003, N.C. Bueno 872 (HUEM); idem, 6-X-2003, N.C. Bueno 883 (HUEM); idem, 4-XI-2003, N.C. Bueno 888 (HUEM); idem, 8-XII-2003, N.C. Bueno 904 (HUEM); idem, 5-IV-2004, N.C. Bueno 925 (HUM); Estação 4, 6-X2003, N.C. Bueno 884 (HUEM); Estação 5, 1-IX2003, N.C. Bueno 874 (HUEM); idem, 6-X-2003, N. C. Bueno 885 (HUEM); idem, 5-IV-2004, N.C. Bueno 928 (HUEM).

Staurastrum hirsutum (Ehrenberg) Brébisson in Ralfs, Brit. Desm. 127. 1848 三 Xanthidium hirsutum Ehrenberg, Phys. Abh. K. Acad. Wiss. Berlin 1833, p. 318. (1835) 1836.

Figura 25

Célula 1,4-1,8 mais longa que larga, 26-39,2 $\mu \mathrm{m}$

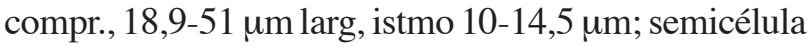
oval, constrição mediana profunda, aberta; margens laterais convexas, margem apical convexa; parede celular com espinhos distribuídos concentricamente, exceto não região do istmo; vista apical 3 angular, margens convexas, parede celular com espinhos.

Materiais examinados: BRASIL. Paraná: Santa Helena, rio São Francisco Falso, Estação 5, 5-IV-2004, N.C. Bueno 928 (HUEM); idem, 17-VI-2004, N.C. Bueno 940 (HUEM).

Staurastrum leptacanthum Nordestedt var. borgei Förster, Amazoniana 2(1/2): 86. 1989.

Figura 26

Célula tão comprida ou 1,1 vezes mais longa que larga, incluindo os processos, 108-130 $\mu \mathrm{m}$ compr., 104-120 um larg. (com espinhos), istmo 18,0-28,0 $\mu \mathrm{m}$; semicélula globosa, constrição mediana em forma de $\mathrm{V}$; margem apical truncada, reta entre os processos; processos longos, 3-denticulados, formando um anel mediano com 9 processos na porção mediana e 6 na porção apical da semicélula; parede celular pontuada; vista apical de contorno aproximadamente circular, margens estreitas entre os 9 processos, margens ornadas com 3 espinhos robustos no ápice.

Materiais examinados: BRASIL. PARANÁ: Santa Helena, rio São Francisco Falso, Estação 2, 6-X-2003, N.C. Bueno 882 (HUEM); Estação 3, 5-IV-2004, N. C. Bueno 926 (HUEM); Estação 5, 4-XI-2003, N.C. Bueno 890 (HUEM); idem, 8-XII-2003, N.C. Bueno 906 (HUEM); idem,10-III-2004, N.C. Bueno 921 (HUEM). 
Staurastrum leptocladum Nordstedt var. insigne G.M. Smith, Trans. Wis. Acad. Sci. Arts Lett. 20: 351. 1922.

Figura 27

Célula 2,3-2,8 vezes mais larga que longa, incluindo os processos, 44,9-51,1 $\mu \mathrm{m}$ compr., 102142,8 $\mu \mathrm{m}$ larg. (com espinhos), istmo 4,1-6,7 $\mu \mathrm{m}$ de larg.; semicélula subtriangulares, margens laterais divergentes, crenuladas, margem apical convexa, ângulos com processos longos, divergentes, com 2 espinhos; vista apical bipolar.

Materiais examinados: BRASIL. PARAnÁ: Santa Helena, rio São Francisco Falso, Estação 3, 1-IX2003, N.C. Bueno 872 (HUEM); idem, 6-X-2003, N.C. Bueno 883 (HUEM); idem, 10-III-2004, N.C. Bueno 919 (HUEM); Estação 5, 5-IV-2004, N.C. Bueno 928 (HUEM).

Staurastrum leptocladum var. insigne difere da variedade típica da espécie por apresentar processos mais curvados, margem lateral crenulada ou ornada com verrugas, margem superior com uma série intramarginal de 4-6 verrugas e presença de uma protuberância mais ou menos circular na face das semicélulas.

Staurastrum margaritaceum (Ehrenberg) Ralfs var. margaritaceum, Brit. Desm. 134. 1848 三 Pentasterias margaritacea Ehrenberg, Infus:144. 15. 1838.

Figura 28

Célula 1,2-1,3 vezes mais larga que longa, incluindo os processos, 26,5-34,7 $\mu \mathrm{m}$ compr., 30,6-45 $\mu \mathrm{m}$ larg. (com processo), istmo 8,2-9,0 $\mu \mathrm{m}$; semicélula obtrapeziforme, constrição mediana profunda, margens laterais levemente convexas, lisas, margem apical levemente convexa ou truncada, elevada; 6 processos longos, robustos, 3-denticulados, margens serreadas; parede celular com grânulos limitados aos processos; vista apical 6-angular, margens retusas, lisas entre os processos, longos, 3-denticulados.

Materiais examinados: BRASIL. Parané: Santa Helena, rio São Francisco Falso, Estação 2, 1-VII2003, N.C. Bueno 855 (HUEM); idem, 6-X-2003, N.C. Bueno 882 (HUEM); idem, 6-X-2003, N.C. Bueno 883 (HUEM); idem, 4-XI-2003, N.C. Bueno 888 (HUEM); idem, 8-XII-2003, N.C. Bueno 904 (HUEM); Estação 4, 6-X-2003, N.C. Bueno 884 (HUEM).
Staurastrum minnesotense Wolle var. minnesotense, Bull. Torr. bot. Club 12(1): 6. 1885.

Figura 29

Célula 1,1-1,2 vezes mais longa que larga, 36-75,2 $\mu \mathrm{m}$ compr., 34-64 $\mu \mathrm{m}$ larg. (sem esp.), istmo 10-16,8 $\mu \mathrm{m}$, esp. 16,8-18,4 $\mu \mathrm{m}$; semicélula transversalmente elíptica, constrição mediana profunda, margens apical e laterais convexas, ângulos e região superior da semicélula ornados com espinhos; parede celular finamente pontuada, 1 protuberância mediana com espinhos.

Materiais examinados: BRASIL. ParanÁ: Santa Helena, rio São Francisco Falso, Estação 2, 1-VII2003, N.C. Bueno 855 (HUEM); idem, 3-II-2004, N.C. Bueno 913 (HUEM); idem, 5-IV-2004, N.C. Bueno 925 (HUEM); Estação 5, 5-IV-2004, N.C. Bueno 928 (HUEM); idem, 17-VI-2004, N.C. Bueno 940 (HUEM).

Staurastrum muticum (Brébisson) Ralfs var. muticum, Brit. Desm. 125. 1848 三Binatella muticum Brébisson in Brébisson \& Godey, Mém. Soc. Acad. Sci. Falaise 57. 1835.

Figura 30

Célula 1,2-1,3 vezes mais longa que larga, 26,428,8 $\mu \mathrm{m}$ compr., 21-24,8 $\mu \mathrm{m}$ larg., istmo 8-10,2 $\mu \mathrm{m}$; semicélula subreniforme, constrição mediana profunda, margens apical e laterais convexas; vista apical triangular, margens côncavas, lisas entre os ângulos arredondados.

Materiais examinados: BRASIL. PARANÁ: Santa Helena, rio São Francisco Falso, Estação 2, 6-X-2003, N.C. Bueno 882 (HUEM); Estação 3, 1-IX-2003, N.C. Bueno 872 (HUEM); idem, 6-X-2003, N.C. Bueno 883 (HUEM); Estação 5, 8-XII-2003, N.C. Bueno 906 (HUEM).

Staurastrum nudibrachiatum Borge, Ark. Bot. 1: 109. 1903.

Figura 31

Célula 1,5-1,7 vezes mais larga que longa, incluindo os processos, 51-59,2 $\mu \mathrm{m}$ compr., 77,5$100,0 \mu \mathrm{m}$ larg. (com processo), istmo 27,2-28,5 $\mu \mathrm{m}$; semicélula globosa, constrição mediana profunda, margens laterais e apical convexas, ângulos com 1 processo longo, 3 processos curtos na porção mediana da semicélula, com 2 espinhos; parede celular finamente pontuada. 
Material examinado: BRASIL. PARAnÁ: Santa Helena, rio São Francisco Falso, Estação 5, 5-IV-2004, N.C. Bueno 928 (HUEM).

Staurastrum orbiculare (Ehrenberg) Ralfs var. orbiculare, Brit. Desm. 125. 1848 三 Desmidium orbiculare Ehrenberg, Phys. Abh. Akad. Wiss. 292. 1834.

Figura 32

Célula 1,1 vezes mais longa que larga, 44,8 $\mu \mathrm{m}$ compr., 41,6 $\mu \mathrm{m}$ larg., istmo 10,2 $\mu \mathrm{m}$; semicélula subcircular, constrição mediana profunda, margens laterais e apical convexas, lisas; parede celular finamente pontuada; vista apical triangular, margens laterais retas a levemente retusas, ângulos arredondados.

Materiais examinados: BRASIL. Paraná: Santa Helena, rio São Francisco Falso, Estação 2, 6-X-2003, N.C. Bueno 882 (HUEM); Estação 4, 1-VII-2003, N.C. Bueno 857 (HUEM); Estação 5, 5-IV-2004, N.C. Bueno 928 (HUEM).

Staurastrum punctulatum (Brébisson) Ralfs var. punctulatum, Brit. Desm. 133. 1848 = Cosmarium punctulatum Brébisson, Mém. Soc. imp. Sci. nat. Cherbourg 4: 129, pl. 1, fig. 16.1856.

Figura 33

Célula 1,1-1,2 vezes mais longa que larga, 26,530,4 um compr., 22,4-28,6 um larg., istmo 8,2-12,2 $\mu \mathrm{m}$; semicélula transversalmente elíptica, constrição mediana profunda, margens laterais retas, serreadas; margem apical convexa, serreada, ângulos arredondados; parede celular uniformemente granulosa, grânulos dispostos de forma concêntrica, 1 protuberância mediana; vista apical triangular, margens serreadas, levemente retas entre os ângulos arredondados, grânulos dispostos de forma concêntrica.

Materiais examinados: BRASIL. Paraná: Santa Helena, rio São Francisco Falso, Estação 2, 19-I2004, N.C. Bueno 908 (HUEM); idem, 5-IV-2004, N.C. Bueno 925 (HUEM); Estação 3, 1-VII-2003, N.C. Bueno 816 (HUEM); idem, 4-XI-2003, N.C. Bueno 888 (HUEM); idem, 8-XII-2003, N.C. Bueno 904 (HUEM); Estação 5, 5-IV-2004, N.C. Bueno 928 (HUEM).

Staurastrum quadrangulare (Brébisson) Ralfs var. quadrangulare, Brit. Desm. 128. $1848 \equiv$
Staurastrum quadrangulare Brébisson espécime "majus", Mém. Soc. imp. Sci. nat. Cherbourg 4: 138, pl. 22, fig. 7.1856.

Figura 34

Célula 1,1-1,3 vezes mais longa que larga, 19,228,5 $\mu \mathrm{m}$ compr., 15,2-27,2 $\mu \mathrm{m}$ larg. (com espinho), istmo 7,2-11,2 $\mu \mathrm{m}$; semicélula sub-retangular, constrição mediana rasa, margens laterais levemente côncavas, ângulos basais com 2 espinhos, curtos; margem apical truncada a levemente convexa, ângulos com 2 espinhos, curtos; parede celular lisa, vista apical 4-angular, margens côncavas, lisas entre os ângulos, ângulos truncados, com 2 pares de espinhos justapostos.

Materiais examinados: BRASIL. PARANÁ: Santa Helena, rio São Francisco Falso, Estação 1, 1-IX2003, N.C. Bueno 870 (HUEM); Estação 2, 6-X-2003, N.C. Bueno 882 (HUEM); Estação 3, 5-IV-2004, N.C. Bueno 926 (HUEM); Estação 5, 5-IV-2004, N.C. Bueno 928 (HUEM).

Staurastrum sebaldi var. ornatum Nordstedt, Acta Univ. Lund 9: 34. 1873.

Figura 35

Célula 1,1-1,3 vezes mais longa que larga,

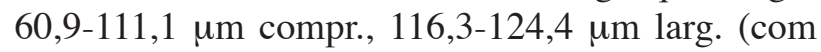
espinho), istmo 15,3-26,5 $\mu \mathrm{m}$; semicélula ciatiforme, constrição mediana invaginada em forma de "V", margens laterais levemente convexa, divergindo para os ângulos apicais formando processos curvados, longos, truncados, com um par de verrugas pequenas, conspícuas ao longo dos processos, 3 espinhos no ápice, margem apical convexa, base da semicélula com grânulos acima do istmo sob cada processo; vista apical 3-angular, margens côncavas entre os ângulos, lisa, série intramarginal de verrugas nos processos.

Materiais examinados: BRASIL. PARANÁ: Santa Helena, rio São Francisco Falso, Estação 2, 6-X-2003, N.C. Bueno 882 (HUEM); Estação 3, 1-IX-2003, N.C. Bueno 872 (HUEM); idem, 5-IV-2004, N.C. Bueno 926 (HUEM); idem, 4-V-2004, N.C. Bueno 933 (HUEM); Estação 4, 1-VII-2003, N.C. Bueno 857 (HUEM); Estação 5, 1-VII-2003, N.C. Bueno 858 (HUEM); idem, 19-I-2004, N.C. Bueno 911 (HUEM); idem, 3-II-2004, N.C. Bueno 916 (HUEM); idem, 5-IV-2004, N.C. Bueno 928 (HUEM); idem, 4-V2004, N.C. Bueno 935 (HUEM); idem, 17-VI-2004, N.C. Bueno 940 (HUEM). 
Staurastrum setigerum Cleve var. setigerum, Öfv.

Kongl. Vet.-Akad. Förhandl.10: 490. 1864.

Figura 36

Célula 1,0-1,1 vezes mais longa que larga, 33$36 \mu \mathrm{m}$ compr., 31-34 $\mu \mathrm{m}$ larg. (sem espinho), istmo 10-12 $\mu \mathrm{m}$; semicélula elípticas, constrição mediana profunda, ápice em forma de "U”, margens laterais convexas, ângulos com 2 espinhos proeminentes, agudos, margem apical convexa com 5-6 espinhos, agudos, séries transversais de espinhos a partir da margem apical, um espinho acima do istmo.

Materiais examinados: BRASIL. Paraná: Santa Helena, rio São Francisco Falso, Estação 2, 1-IX2003, N. C. Bueno 871 (HUEM); idem, 3-II-2004, N.C. Bueno 913 (HUEM).
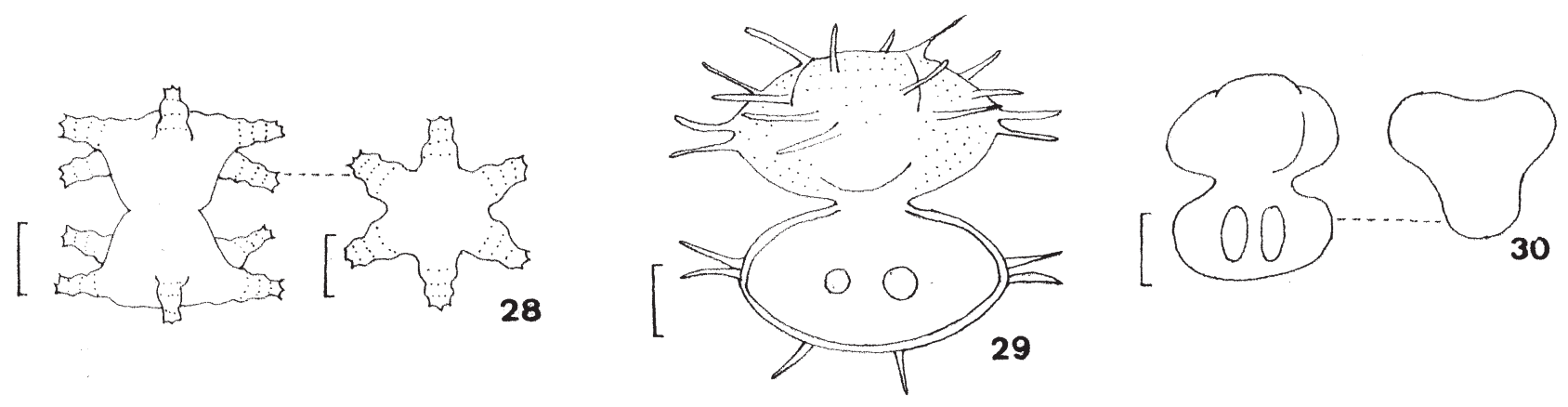
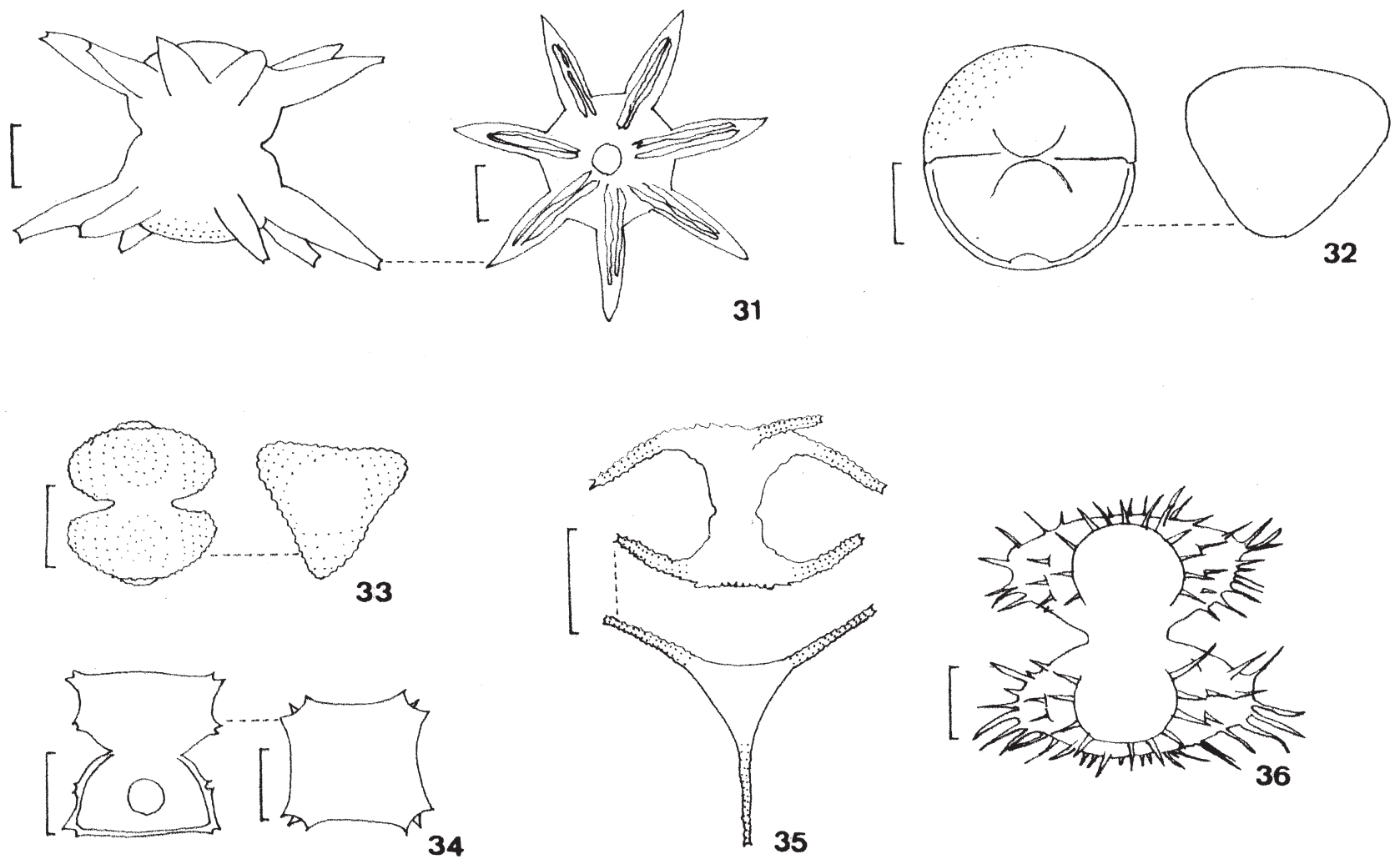

34

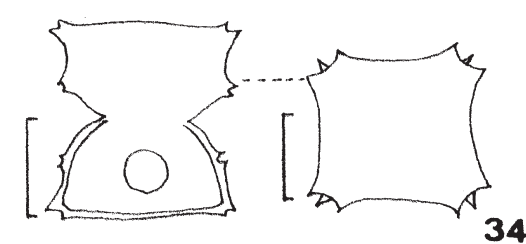

Figura 28. Staurastrum margaritaceum var. margaritaceum (barra $=10 \mu \mathrm{m})$. Figura 29. Staurastrum minnesotense var. minnesotense $($ barra $=10 \mu \mathrm{m})$. Figura 30. Staurastrum muticum var. muticum $($ barra $=10 \mu \mathrm{m})$. Figura 31. Staurastrum nudibrachiatum $($ barra $=16,3$ $\mu \mathrm{m})$. Figura 32. Staurastrum orbiculare var. orbiculare $($ barra $=16 \mu \mathrm{m})$. Figura 33. Staurastrum punctulatum var. punctulatum $($ barra $=$ $15 \mu \mathrm{m})$. Figura 34. Staurastrum quadrangulare var. quadrangulare (barra $=10 \mu \mathrm{m})$. Figura 35. Staurastrum sebaldi var. ornatum (barra $=50 \mu \mathrm{m})$. Figura 36. Staurastrum setigerum var. setigerum $($ barra $=10 \mu \mathrm{m})$. 
Staurodesmus connatus (Lundell) Thomasson, Nova Acta Regiae Soc. Sci. Upsal. 4(17): $34.1960 \equiv$ Staurastrum dejectum Brébisson var. connatum Lundell, Nova Acta Regiae Societatis Scientiarum Upsaliensis: ser. 3, 8: 60, pl. 3, fig. 28. 1972.

Figura 37

Célula 1,6-2,4 vezes mais longa que larga, 22,532,2 $\mu \mathrm{m}$ compr., 25,7-29 $\mu \mathrm{m}$ larg. (com espinho), istmo 4,8-9,6 $\mu \mathrm{m}$; semicélula mais ou menos ciatiforme, constrição mediana profunda, margens laterais assimetricamente convexas, ângulos acuminados com 1 espinho pontiagudo, curto, amplamente divergente, margem apical levemente convexa; parede celular lisa; vista apical 3-angular, ângulos acuminadosarredondados com 1 espinho curto.

Materiais examinados: BRASIL. Paraná: Santa Helena, rio São Francisco Falso, Estação 1, 5-IV-2004, N.C. Bueno 924 (HUEM); Estação 5, 5-IV-2004, N.C. Bueno 928 (HUEM).

Staurodesmus connatus difere de $S$. dejectus (Brébisson) Teiling pela presença de espinhos mais longos e istmo alongado. S. connatus apresenta os espinhos curtos e o seno é acutangular e aberto.

Staurodesmus dickiei (Ralfs) Lillieroth var. dickiei, Acta Limnol. 3: 264. 1950 =Staurastrum dickiei Ralfs, Brit. Desm. 123. 1848.

Figura 38

Célula 1,3 vezes mais larga que longa, incluindo os espinhos, 30,5-31-5 $\mu \mathrm{m}$ compr., 39,6-40 $\mu \mathrm{m}$ larg. (com espinho), istmo 8-8,4 $\mu \mathrm{m}$; semicélula de contorno transversalmente elíptico, constrição mediana profunda, margens apical e laterais convexas, ângulos com 1 espinho, convergente; parede celular lisa, vista apical triangular, margens retas entre os ângulos levemente inflados, com 1 espinho.

Materiais examinados: BRASIL. Paraná: Santa Helena, rio São Francisco Falso, Estação 1, 1-VII2003, N.C. Bueno 859 (HUEM); Estação 2, 3-II-2004, N.C. Bueno 913 (HUEM).

Staurodesmus lobatus (Börgesen) Bourrelly var. ellipticus (Fritsch \& Rich) Teiling f. minor (G.S. Smith) Teiling, Ark. Bot. 6(11): 586. $1967 \equiv$ Cosmarium contractum Kirchner var. papillatum West \& West f. minor G. M. Smith, Trans. Wis. Acad. Sci. Arts Lett. 20: 345. 1922.
Figura 39

Célula 1,3 vezes mais longa que larga, 22,5 $\mu \mathrm{m}$

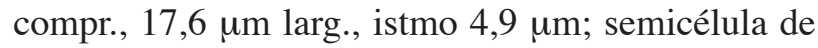
contorno oblongo a elíptico, constrição mediana profunda, margens apical e laterais convexas, lisas, ângulos arredondados, com 1 espinho; parede celular pontuada, espessada.

Material examinado: BRASIL. PARANÁ: Santa Helena, rio São Francisco Falso, Estação 5, 5-IV-2004, N.C. Bueno 928 (HUEM).

Staurodesmus lobatus var. ellipticus f. minor difere da variedade típica da espécie pela presença da célula circular na vista apical.

Staurodesmus mamillatus (Nordstedt) Teiling var. mamillatus, Ark. Bot. 6(11): 536. $1967 \equiv$ Cosmarium contractum Kirchner var. papillatum West \& West f. minor G. M. Smith, Trans. Wis. Acad. Sci. Arts Lett., 20: 345, pl. 10, fig. 2-5. 1922.

Figuras 40-41

Célula 1,1-1,6 vezes mais longa que larga, incluindo os espinhos, 16-28 $\mu \mathrm{m}$ compr., 25-29,6 $\mu \mathrm{m}$ larg. (com espinho), istmo 4-6 $\mu \mathrm{m}$; semicélulas truncadamente triangulares, constrição mediana alongada, seno prolongado em forma de um tubo; margens laterais divergentes; margem apical levemente côncava, ângulos com 1 espinho, divergente ou dirigido horizontalmente; parede celular lisa; vista apical triangular, margens levemente côncavas entre os espinhos.

Materiais examinados: BRASIL. PARANÁ: Santa Helena, rio São Francisco Falso, Estação 5, 8-XII2003, N.C. Bueno 906 (HUEM); idem, 19-I-2004, N.C. Bueno 911 (HUEM); idem, 5-IV-2004, N.C. Bueno 928 (HUEM); idem, 17-VI-2004, N.C. Bueno 940 (HUEM).

Staurodesmus mamillatus var. mamillatus apresenta margem lateral da semicélula retilínea enquanto S. cuspidatus (Brébisson) Teiling apresenta margem lateral da semicélula convexa. No material analisado os espécimes apresentaram variação na orientação dos espinhos, de retilínea a convergente.

Staurodesmus subulatus (Kützing) Thomasson var. nordstedtii (G. M. Smith) Thomasson, Nova Acta Regiae Soc. Sci. Upsal. 3(17): 17. 1957 三 Arthrodesmus subulatus Kützing var. nordstedtii 
G.M. Smith, Bulletin of the Wisconsin Geological and Natural History Survey 57(2): 127. 1924.

Figura 42

Célula 1,2-1,9 vezes mais larga que longa, 27,364,8 $\mu \mathrm{m}$ compr., 31,5-52,8 um larg. (sem esp.), istmo 20-20,8 um; semicélula subelíptica a ciatiforme, constrição mediana profunda; margens laterais convexas, ângulos acuminados com 1 espinho longo, pontiagudo, convergente, margem apical amplamente convexa; parede celular lisa; vista apical 3-angular, margens levemente convexas entre os espinhos, 1 espinho em cada pólo.

Material examinado: BRASIL. PARANÁ: Santa Helena,
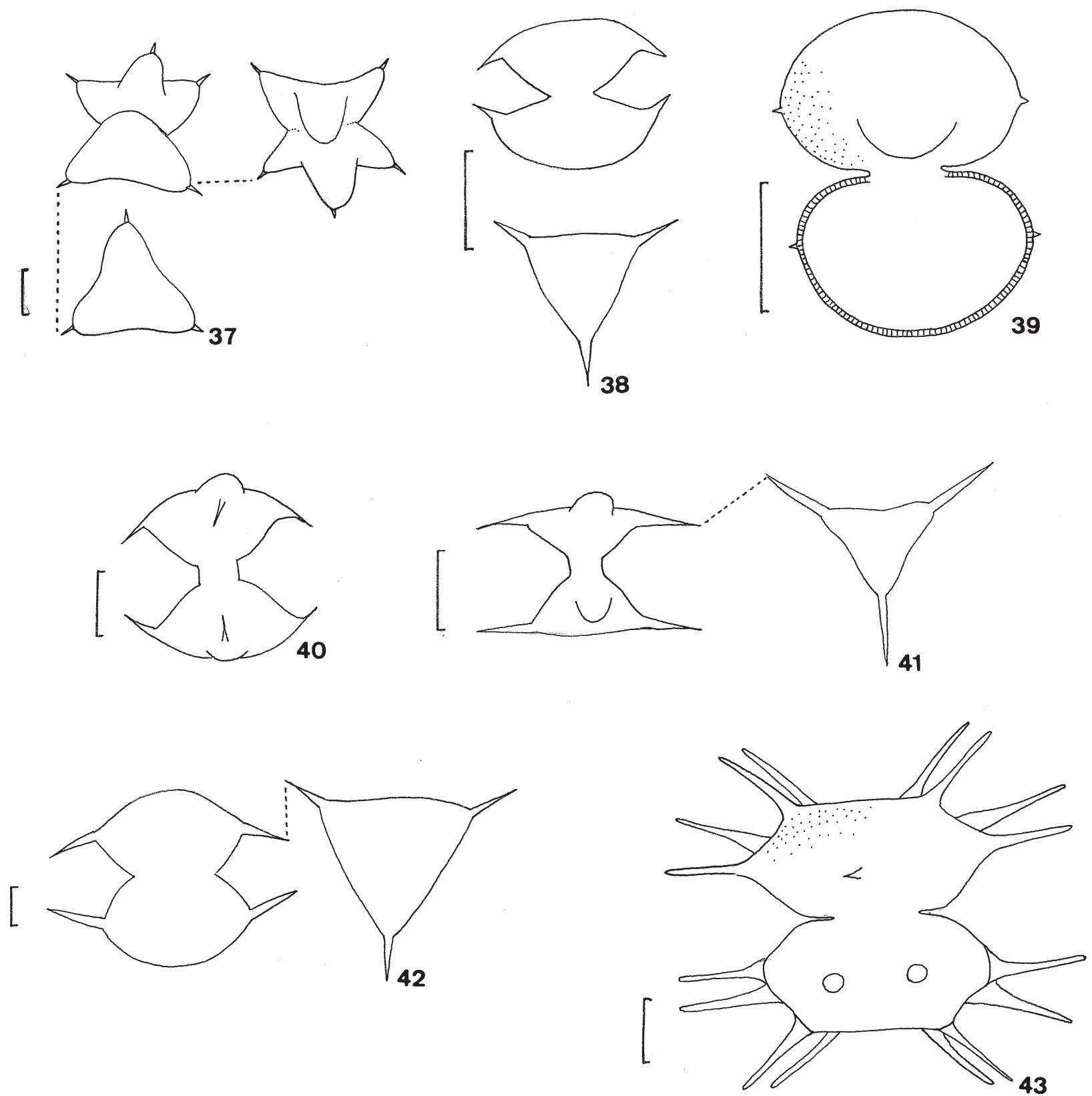

Figura 37. Staurodesmus connatus (barra $=10 \mu \mathrm{m})$. Figura 38. Staurodesmus dickiei var. dickiei (barra $=20 \mu \mathrm{m})$. Figura 39. Staurodesmus lobatus var. ellipticus f. minor (barra $=9 \mu \mathrm{m}$ ). Figura 40. Staurodesmus mamillatus var. mamillatus 41. Staurodesmus mamillatus var. mamillatus, vista apical. (barra $=10 \mu \mathrm{m})$. Figura 42. Staurodesmus subulatus var. nordstedtii (barra $=10 \mu \mathrm{m})$. Figura 43 . Xanthidium antilopaeum var. canadense (barra $=20 \mu \mathrm{m})$. 
Tabela 1. Distribuição dos táxons (Desmidiaceae, Zygnemaphyceae) nas cinco estações de coleta durante o período de estudo (julho de 2003 a junho de 2004) no rio São Francisco Falso, Paraná, Brasil.

\begin{tabular}{|c|c|c|c|c|c|c|c|c|c|c|c|c|c|c|c|c|c|}
\hline \multirow{3}{*}{ Táxons } & \multirow{2}{*}{\multicolumn{5}{|c|}{ Estações de coleta }} & \multicolumn{12}{|c|}{ Meses } \\
\hline & & & & & & \multicolumn{6}{|c|}{2003} & \multicolumn{6}{|c|}{2004} \\
\hline & E1 & E2 & E3 & $\mathrm{E} 4$ & E5 & $\mathrm{J}$ & A & S & $\mathrm{O}$ & $\mathrm{N}$ & $\mathrm{D}$ & $\mathrm{J}$ & $\mathrm{F}$ & M & A & M & $\mathrm{J}$ \\
\hline Actinotaenium wollei var. wollei & & $\mathrm{x}$ & $\mathrm{x}$ & & & & & $\mathrm{x}$ & $\mathrm{x}$ & $\mathrm{x}$ & & & $\mathrm{x}$ & & & & \\
\hline Closterium dianae var. dianae & & $\mathrm{x}$ & & $\mathrm{x}$ & $\mathrm{x}$ & $\mathrm{x}$ & & $\mathrm{x}$ & $\mathrm{x}$ & & & & & $\mathrm{x}$ & $\mathrm{x}$ & & \\
\hline C. incurvum var. incurvum & $\mathrm{x}$ & $\mathrm{x}$ & & & $\mathrm{x}$ & & & $\mathrm{x}$ & $\mathrm{x}$ & $\mathrm{x}$ & $\mathrm{x}$ & & & & & & \\
\hline C. moniliferum var. moniliferum & $\mathrm{x}$ & $\mathrm{x}$ & $\mathrm{x}$ & $\mathrm{x}$ & & $\mathrm{x}$ & & $\mathrm{x}$ & $\mathrm{x}$ & & $\mathrm{x}$ & $\mathrm{x}$ & $\mathrm{x}$ & $\mathrm{x}$ & & $\mathrm{x}$ & $\mathrm{x}$ \\
\hline Euastrum abruptum var. abruptum & & $\mathrm{x}$ & $\mathrm{x}$ & $\mathrm{x}$ & $\mathrm{x}$ & $\mathrm{x}$ & & $\mathrm{x}$ & $\mathrm{x}$ & & & & & & $\mathrm{x}$ & & \\
\hline E. abruptum var. lagoense & $\mathrm{x}$ & $\mathrm{x}$ & & & $\mathrm{x}$ & $\mathrm{x}$ & & $\mathrm{x}$ & $\mathrm{x}$ & & & $\mathrm{x}$ & & & & & \\
\hline E. quebecense & & $\mathrm{x}$ & $\mathrm{x}$ & & $\mathrm{x}$ & & & $\mathrm{x}$ & $\mathrm{x}$ & $\mathrm{x}$ & $\mathrm{x}$ & & $\mathrm{x}$ & & & $\mathrm{x}$ & \\
\hline E. rectangulare & & $\mathrm{x}$ & & $\mathrm{x}$ & $\mathrm{x}$ & $\mathrm{x}$ & & $\mathrm{x}$ & $\mathrm{x}$ & & & & & & $\mathrm{x}$ & & \\
\hline E. subintegrum var. brasiliense & & $\mathrm{x}$ & & & & & & & $\mathrm{x}$ & & & & & & & & \\
\hline Micrasterias furcata var. furcata & & $\mathrm{x}$ & & & $\mathrm{x}$ & & & $\mathrm{x}$ & & $\mathrm{x}$ & & $\mathrm{x}$ & & & $\mathrm{x}$ & & $\mathrm{x}$ \\
\hline M. laticeps var. laticeps & & $\mathrm{x}$ & $\mathrm{x}$ & & & $\mathrm{x}$ & & $\mathrm{x}$ & $\mathrm{x}$ & & & & & & & $\mathrm{x}$ & \\
\hline $\begin{array}{l}\text { M. mahabuleshwarensis var. } \\
\text { amazonensis }\end{array}$ & & $\mathrm{x}$ & & $\mathrm{x}$ & $\mathrm{x}$ & $\mathrm{x}$ & & & $\mathrm{x}$ & & & & & & $\mathrm{x}$ & $\mathrm{x}$ & \\
\hline M. rotata & & $\mathrm{x}$ & & & & & & & & & & $\mathrm{x}$ & & & & & \\
\hline M. truncata var. pusilla & $\mathrm{x}$ & $\mathrm{x}$ & $\mathrm{x}$ & $\mathrm{x}$ & $\mathrm{x}$ & $\mathrm{x}$ & & $\mathrm{x}$ & $\mathrm{x}$ & & $\mathrm{x}$ & $\mathrm{x}$ & & & & & $\mathrm{x}$ \\
\hline $\begin{array}{l}\text { Octacanthium mucronulatum var. } \\
\text { mucronulatum }\end{array}$ & & $\mathrm{x}$ & & & & & & & & & & & $\mathrm{x}$ & & & & \\
\hline Onychonema laeve var. laeve & & & & $\mathrm{x}$ & $\mathrm{x}$ & $\mathrm{x}$ & & $\mathrm{x}$ & & & & & & & $\mathrm{x}$ & & \\
\hline $\begin{array}{l}\text { Penium margaritaceum var. } \\
\text { margaritaceum }\end{array}$ & & & $\mathrm{x}$ & & & $\mathrm{x}$ & & $\mathrm{x}$ & & $\mathrm{x}$ & & & & $\mathrm{x}$ & $\mathrm{x}$ & & \\
\hline $\begin{array}{l}\text { Pleurotaenium ehrenbergii var. } \\
\text { ehrenbergii }\end{array}$ & & $\mathrm{x}$ & $\mathrm{x}$ & & $\mathrm{x}$ & & & $\mathrm{x}$ & $\mathrm{x}$ & $\mathrm{x}$ & & & & & $\mathrm{x}$ & & \\
\hline Pleurotaenium sp. & & $\mathrm{x}$ & & & & & & & $\mathrm{x}$ & & & & & & & & \\
\hline $\begin{array}{l}\text { Spondylosium panduriforme var. } \\
\text { limneticum }\end{array}$ & & & & & $\mathrm{x}$ & & & & & & & & $\mathrm{x}$ & & $\mathrm{x}$ & & \\
\hline S. pulchrum var. pulchrum & & $\mathrm{x}$ & & & $\mathrm{x}$ & & & & & & & $\mathrm{x}$ & & & $\mathrm{x}$ & & \\
\hline Staurastrum brasiliense var. brasiliense & & $\mathrm{x}$ & & & $\mathrm{x}$ & & & & $\mathrm{x}$ & & & & & $\mathrm{x}$ & $\mathrm{x}$ & & \\
\hline S. dilatatum var. dilatatum & & $\mathrm{x}$ & $\mathrm{x}$ & $\mathrm{x}$ & $\mathrm{x}$ & & & $\mathrm{x}$ & $\mathrm{x}$ & $\mathrm{x}$ & $\mathrm{x}$ & & & & $\mathrm{x}$ & & \\
\hline S. hirsutum & & & & & $\mathrm{x}$ & & & & & & & & & & $\mathrm{x}$ & & $\mathrm{x}$ \\
\hline S. leptacanthum var. borgei & & $\mathrm{x}$ & $\mathrm{x}$ & & $\mathrm{x}$ & & & & $\mathrm{x}$ & $\mathrm{x}$ & $\mathrm{x}$ & & & $\mathrm{x}$ & $\mathrm{x}$ & & \\
\hline S. leptocladum var. insigne & & & $\mathrm{x}$ & & $\mathrm{x}$ & & & $\mathrm{x}$ & $\mathrm{x}$ & & & & & $\mathrm{x}$ & $\mathrm{x}$ & & \\
\hline S. margaritaceum var. margaritaceum & & $\mathrm{x}$ & $\mathrm{x}$ & $\mathrm{x}$ & & $\mathrm{x}$ & & & $\mathrm{x}$ & $\mathrm{x}$ & $\mathrm{x}$ & & & & & & \\
\hline S. minnesotense var. minnesotense & & $\mathrm{x}$ & & & $\mathrm{x}$ & $\mathrm{x}$ & & & & & & & $\mathrm{x}$ & & $\mathrm{x}$ & & $\mathrm{x}$ \\
\hline S. muticum var. muticum & & $\mathrm{x}$ & $\mathrm{x}$ & & & & & $\mathrm{x}$ & $\mathrm{x}$ & & $\mathrm{x}$ & & & & & & \\
\hline S. nudibrachiatum & & & & & $\mathrm{x}$ & & & & & & & & & & $\mathrm{x}$ & & \\
\hline S. orbiculare var. orbiculare & & $\mathrm{x}$ & & $\mathrm{x}$ & $\mathrm{x}$ & $\mathrm{x}$ & & & $\mathrm{x}$ & & & & & & $\mathrm{x}$ & & \\
\hline S. punctulatum var. punctulatum & & $\mathrm{x}$ & $\mathrm{x}$ & & $\mathrm{x}$ & $\mathrm{x}$ & & & & $\mathrm{x}$ & $\mathrm{x}$ & $\mathrm{x}$ & & & $\mathrm{x}$ & & \\
\hline S. quadrangulare var. quadrangulare & $\mathrm{x}$ & $\mathrm{x}$ & $\mathrm{x}$ & & $\mathrm{x}$ & & & $\mathrm{x}$ & $\mathrm{x}$ & & & & & & $\mathrm{x}$ & & \\
\hline S. sebaldi var. ornatum & & $\mathrm{x}$ & $\mathrm{x}$ & $\mathrm{x}$ & $\mathrm{x}$ & $\mathrm{x}$ & & $\mathrm{x}$ & $\mathrm{x}$ & & & $\mathrm{x}$ & $\mathrm{x}$ & & $\mathrm{x}$ & $\mathrm{x}$ & $\mathrm{x}$ \\
\hline S. setigerum var. setigerum & & $\mathrm{x}$ & & & & & & $\mathrm{x}$ & & & & & $\mathrm{x}$ & & & & \\
\hline Staurodesmus connatus & $\mathrm{x}$ & & & & $\mathrm{x}$ & & & & & & & & & & $\mathrm{x}$ & & \\
\hline S. dickiei var. dickiei & $\mathrm{x}$ & $\mathrm{x}$ & & & & $\mathrm{x}$ & & & & & & & $\mathrm{x}$ & & & & \\
\hline S. lobatus var. ellipticus f. minor & & & & & $\mathrm{x}$ & & & & & & & & & & $\mathrm{x}$ & & \\
\hline S. mamillatus var. mamillatus & & & & & $\mathrm{x}$ & & & & & & $\mathrm{x}$ & $\mathrm{x}$ & & & $\mathrm{x}$ & & $\mathrm{x}$ \\
\hline S. subulatus var. nordstedtii & & & & & $\mathrm{x}$ & & & & & & & & & & & $\mathrm{x}$ & \\
\hline Xanthidium antilopaeum var. canadense & & & & & $\mathrm{x}$ & & & & & & & & & & $\mathrm{x}$ & & \\
\hline
\end{tabular}


rio São Francisco Falso, Estação 5, 5-IV-2004, N.C. Bueno 928 (HUEM).

Xanthidium antilopaeum (Brébisson) Kützing var. canadense Joshua, J. Bot. 23: 34. 1885 三 Xanthidium columbianum Wölle, Bull. Torr. Bot. Club 12(1): 3. 1885; Desm. United States, p. 100, pl. 45, figs. 10-11. 1892.

Figura 43

Célula levemente mais longa que larga, 70 $\mu \mathrm{m}$ compr., $68 \mu \mathrm{m}$ larg. (sem esp.), istmo 26,4 $\mu \mathrm{m}$; semicélula hexagonal, constrição mediana profunda, margens basais convexas, ângulo com 1 par de espinhos longos, retos, de base quase mamiliforme, dispostos um ao lado do outro, margens laterais levemente convexas; margem apical reta, ângulos com 1 par de espinhos semelhantes aos dos ângulos inferiores; 1 espinho curto, reto, na porção mediana da face da semicélula; parede celular finamente pontuada.

Material examinado: BRASIL. PARANÁ: Santa Helena, rio São Francisco Falso, Estação 5, 5-IV-2004, N.C. Bueno 928 (HUEM).

O levantamento florístico realizado no presente estudo registrou Micrasterias truncata var. pusilla como sendo o táxon com melhor distribuição geográfica, a espécie ocorreu em todas as cinco estações de amostragem (tabela 1). Três táxons foram registrados em quatro estações de amostragem: Closterium moniliferum var. moniliferum, Micrasterias truncata var. pusilla e Staurastrum quadrangulare var. quadrangulare. Os táxons que foram registrados para três, duas ou apenas um estação de amostragem estão representados juntamente com os demais táxons mais abundantes na tabela 1 . As estações de coleta 2 e 5 e os meses de setembro e outubro de 2003 e abril de 2004, registraram o maior número de táxons de desmídias. Entre os táxons identificados, houve predomínio das formas unicelulares. Foram encontradas poucas desmídias coloniais e nenhuma de hábito filamentoso.

\section{Agradecimentos}

Ao CNPq-PIBIC/UNIOESTE/Cascavel/PR pela bolsa de iniciação científica concedida à primeira autora e ao Laboratório de Perifíton do Nupélia, Núcleo de Pesquisas em Limnologia Ictiologia e Aqüicultura, Universidade Estadual de Maringá, pelo suporte técnico-científico.

\section{Literatura citada}

Agostinho, A.A., Okada, E.K. \& Gregoris, J. 1999. A Pesca no Reservatório de Itaipu: Aspectos Socioeconômicos e Impactos do Represamento. In: R. Henry (ed.). Ecologia de Reservatórios: Estrutura, Função e Aspectos Sociais. FAPESP/FUNDIBIO, Botucatu.

Algarte,V.M., Moresco, C. \& Rodrigues, L. 2006. Algas do perifíton de distintos ambientes na planície de inundação do alto rio Paraná. Acta Scientiarum 28: 243-251.

Bicudo, C.E.M. \& Menezes, M. 2006. Gêneros de algas de águas continentais do Brasil: chave para identificação e descrições. RiMa, São Carlos.

Bittencourt-Oliveira, M.C. 1993a. Ficoflórula do Rio Tibagi, Estado do Paraná, Brasil I: Desmídias Filamentosas e Gêneros Gonatozygon, Penium, Pleurotaenium e Tetmemorus (Zygnemaphyceae). Semina (Ciências Biológicas) 14: 61-73.

Bittencourt-Oliveira, M.C. 1993b. Ficoflórula do Rio Tibagi, Estado do Paraná, Brasil III: gêneros Actinotaenium, Cosmarium e Staurodesmus (Zygnemaphyceae). Semina (Ciências Biológicas) 14: 86-95.

Bittencourt-Oliveira, M.C. \& Castro, A.A.J. 1993. Ficoflórula do Rio Tibagi, Estado do Paraná, Brasil, II: gênero Closterium (Zygnemaphyceae). Semina (Ciências Biológicas) 14: 74-85.

Bittencourt-Oliveira, M.C. \& Mecenas, P.R. 1994. Ficoflórula do Rio Tibagi, Estado do Paraná, Brasil, IV: gêneros Micrasterias, Staurastrum e Xanthidium (Zygnemaphyceae). Semina (Ciências Biológicas) 15(2): 133-152.

Cecy, I.I.T. 1993. Expressões morfológicas observadas em Pleurotaenium ehrenbergii (Brébisson) De Bary, procedentes da Restinga de Pontal do Sul, Município de Paranaguá, Paraná. Estudos de Biologia 30: 5-20.

Cecy, I.I.T, Silva, S.R.V.F. \& Boccon, R. 1997. Fitoplâncton da Represa do Rio Passaúna, Município de Araucária, Estado do Paraná. I - Divisão Chlorophyta Família Desmidiaceae. Estudos de Biologia 41: 5-32.

Ceto, J.M., Leandrini, J.A., Felisberto, S.A. \& Rodrigues, L. 2004. Comunidade de algas perifíticas no reservatório de Irai, Estado do Paraná, Brasil. Acta Scientiarium (Biological Sciences) 26: 1-7.

Felisberto, S.A. 2003. Composição e abundância de desmídias perifiticas caracterizando reservatórios e suas regiões ao longo do eixo rio-barragem. Dissertação de Mestrado, Universidade Estadual de Maringá, Maringá.

Felisberto, S.A. \& Rodrigues, L. 2002. Desmidiales (exceto o gênero Cosmarium) perifíticas no reservatório de Corumbá, Goiás, Brasil. Iheringia (Série Botânica) 57: 75-97. 
Felisberto, S.A. \& Rodrigues, L. 2005. Comunidade de algas perifíticas em reservatórios de diferentes latitudes. In: L.Rodrigues, S.M. Thomaz, A.A.Agostinho, L.C. Gomes (orgs.). Biocenose em reservatórios: padrões espaciais e temporais. RiMa, São Carlos, pp. 97-114.

Felisberto, S.A. \& Rodrigues, L. 2007. Gênero Closterium (Closteriaceae) na comunidade perifítica do Reservatório de Salto do Vau, sul do Brasil. Iheringia (Série Botânica) 62: 45-54.

Margalef, R. 1983. Limnología. Omega, Barcelona.

Picelli-Vicentim, M.M. 2001. Fitoplâncton da Represa do Passaúna, Estado do Paraná, Brasil. Hoehnea 28: 53-76.
Silva, S.R.V.F. \& Cecy, I.I.T. 2004. Desmídias (Zygnemaphyceae) da área de abrangência da Usina Hidrelétrica de Salto Caxias, Paraná, Brasil, I: Gênero Cosmarium. Iheringia (Série Botânica) 59: 13-26.

Sormus, L. \& Bicudo, C.E.M. 1994. Criptógamos do Parque Estadual das Fontes do Ipiranga, São Paulo, SP. Algas, 6: Zygnemaphyceae (Closteriaceae). Hoehnea 21: 75-92.

Teiling, E. 1952. Evolutionary studies on the shape of the cell and chloroplast in desmids. Botaniska Notiser 1952: 264-306.

Wehr, J.D. \& Sheat, R.G. 2003. Freshwater Algae of North America. Ecology and Classification. Academic Press, New York. 